10 Burleigh-Flayer $\mathrm{H}$, Wong $\mathrm{KL}$, Alarie $\mathrm{Y}$. Evaluation of the pulmonary effects of $\mathrm{HCl}$ using $\mathrm{CO}_{2}$ challenges in guinea pulmonary effects of $\mathrm{HCl}$ using $\mathrm{CO}_{2}$ chall
pigs. Fund Appl Toxicol 1985;5:978-85.

11 Kaplan HL, Anzueto A, Switzer WG, Hinderer RK. Effects of hydrogen chloride on respiratory response and pulmonary function of the baboon. $₹$ Toxicol Environ Health 1988; 23:473-93.
12 Stavert DM, Archuleta DC, Behr MJ, Lehnert BE. Relative acute toxicities of hydrogen fluoride, hydrogen chloride, and hydrogen bromide in nose- and pseudomouthbreathing rats. Fund Appl Toxicol 1991;16:636-55.

13 Stevens B, Koenig JQ, Rebolledo V, Hanley QS, Covert DS Respiratory effects from the inhalation of hydrogen chloride in young adult asthmatics. $\mathcal{F}$ Occup Med 1992;34:923-9.

\title{
The rising prevalence of HIV-1 infection in patients attending an inner city accident and emergency department
}

Mark C Poznansky, Jon Walters, Alistair Cruikshank, Robin Pollock, Peter Dendrowskyj, Kim Lewis, John V Parry, Jane Fothergill, Jonathan Weber

The recently published findings of the unlinked anonymous HIV prevalence study in England and Wales showed unchanging HIV prevalence in groups such as homo/bisexual men, and declining rates in non-injecting heterosexual men attending genitourinary medicine clinics. ${ }^{1}$ However, this multicentre study did detect a significant rise in seroprevalence rates in pregnant women in England and Wales and sentinel groups within hospitals in London, warning that changing patterns of HIV infection might account for these variable results. In 1992-1993 a seroprevalence study of adult patients attending the accident and emergency department at St. Mary's Hospital in West Central London showed a rate of HIV-1 infection of 1 in $77 . .^{2}$ We have repeated the seroprevalence study over the same calendar months in 1994-1995 to gain further information about HIV positive patients attending the department and to see whether a change in the patterns of HIV infection in the population served by $\mathrm{St}$ Mary's Hospital had occurred.

\section{Methods and results}

Anonymised blood or urine samples were obtained from 1087 consecutive new patients attending the accident and emergency (A\&E) department at St Mary's Hospital between 14 December 1994 and the 31 January 1995. No repeat samples were obtained from reattendees. The collection and numbering of samples conformed to the requirements of the Health Authority ethics committee. Each patient's sex, age, postal district of residence, general practitioner, and triage group were noted, in addition to whether the patients declared their HIV positivity while in A\&E. Data were collected on whether procedures which might involve exposure to blood were performed on each patient and also the subsequent destination of patients (that is, discharged or admitted to medical, surgical, or HIV medicine wards). ${ }^{3}$ In addition, these details were obtained for patients who did not agree to participate in the study ( $\mathrm{n}=8,0.25 \%)$. No patients were included in the study who were directly referred to the medical, surgical, or the HIV medicine team. The adequacy of urine and blood samples and the rigorous conditions for testing samples for anti HIV-1 and HIV-2 antibodies (that is, IgG quantitation, enzyme linked immunosorbent assays, and western blotting) were performed as before. ${ }^{2}$ The results of the study are shown in the table. The seroprevalence rate of $\mathrm{HIV}-1$ infection has risen to 1 in 30 for male and female patients

Hospital Medical

School, London W2

M C Poznansky

$\mathrm{J}$ Weber

Hepatitis and

Retrovirus Laboratory,

PHLS Virus Reference

Division, Central

Public Health

Laboratory, London

NW9

J V Parry

K Lewis

Correspondence to:

Dr Mark Poznansky, Jefferiss

Research Trust Laboratories,

St Mary's Hospital Medical

School, Praed Street,

London W2 1 NY.

Accepted for publication 24 April 1996

\begin{tabular}{|c|c|c|c|}
\hline & HIV negative (\%) & HIV positive (\%) & Pvalue \\
\hline \multicolumn{4}{|c|}{ Number of patients providing urine or blood samples } \\
\hline IgG $>0.1 \mathrm{mg} / \mathrm{ml}$ & $1066(98.2)$ & $19(1.8)$ & \\
\hline Number $(\%)(95 \% \mathrm{CI})$ of men & $624(56)(51.6$ to 60.4$)$ & $14(74)(72.9$ to 75.1$)$ & $<0.001$ \\
\hline Number $(\%)(95 \% \mathrm{CI})$ of women & $442(44)(40.9$ to 47.1$)$ & $5(26)(25.8$ to 26.2$)$ & $<0.01$ \\
\hline \multicolumn{4}{|l|}{ Number $(\%)(95 \% \mathrm{CI})$ of age } \\
\hline $16-25$ years & $224(21)(17.5$ to 24.5$)$ & $1(5)(4.7$ to 5.3$)$ & NS \\
\hline $25-49$ years & $352(33)(28.8$ to 37.2$)$ & $18(95)(94.0$ to 96.0$)$ & $<0.001$ \\
\hline 49-99 years & $490(46)(41.6$ to 50.4$)$ & $0(0)$ & $<0.001$ \\
\hline Number $(\%)(95 \% \mathrm{CI})$ with GP & 757 (71) $(66.8$ to 75.2$)$ & $12(63)(62.1$ to 63.9$)$ & NS \\
\hline Number $(\%)(95 \% \mathrm{CI})$ foreign visitor & $213(20)(16.7$ to 23.3$)$ & $4(21)(20.3$ to 21.7$)$ & NS \\
\hline Number (\%) $(95 \% \mathrm{CI})$ with open wound & 181 (17) (13.7 to 20.3$)$ & $5(26)$ & NS \\
\hline Number (\%) major illness triage category & $354(34)$ & $12(63)$ & $<0.001$ \\
\hline Number (\%) declared HIV positive & $0(0)$ & $5(25)$ & $<0.001$ \\
\hline \multicolumn{4}{|l|}{ Number (\%) admitted under } \\
\hline Medical team & $95(9)$ & $2(10)$ & NS \\
\hline Surgical team & $27(2.5)$ & $0(0)$ & NS \\
\hline HIV medicine team & $0(0)$ & $2(10)$ & NS \\
\hline
\end{tabular}

CI, confidence interval.

${ }^{\star} \chi^{2}$ test, $\mathrm{df}=1$. 
aged between 16 and 45 in the A\&E department, which sees up to 30000 new patients in this age group per year. No samples were found to be positive for HIV-2 antibodies.

\section{Discussion}

The majority of HIV positive patients detected in this study were men aged between 26 and 45 years, who presented to $A \& E$ with major illness potentially requiring immediate hospital admission and who did not report their HIV status to A\&E staff. The proportion of HIV positive patients who were categorised as foreign visitors had fallen significantly from $75 \%$ to $21 \%(P=0.012)$ in 1992 and 1994 , respectively. The fact that two of the 19 patients detected as HIV positive by this study were admitted to general medical wards with acute illnesses but without knowledge of their HIV status emphasises the importance of carrying a high index of suspicion of HIV infection and
HIV related disease from $A \& E$ into the general medical wards. ${ }^{45}$

We thank Jane Wadsworth for help with the statistical analysis of the data and the nursing staff in the Accident and Emergency the data and the nursing staff in the Accident and Emergency
department at St Mary's for their help and co-operation with this study.

1 Unlinked anonymous HIV prevalence monitoring programme: England and Wales - data to the end of 1993. Report from the unlinked anonymous HIV surveys steering Report from the unlinked anonymous HIV surveys steering Health.

2 Heptonstall J, Gill ON, Porter K, Black MB, and Gilbart V. Health care workers and HIV: surveillance of occupationally acquired infection in the United Kingdom. CDR Review. 3. R 147.

3 Poznansky MC, Torkington J, Turner G, Bankes MJK, Parry JV, Connell JA. Prevalence of HIV infection in patients attending an inner city accident and emergency department. $B M \mathscr{f}$ 1994;308:636.

4 Poznansky M, Coker RJ, Skinner C, Hill A, Bailey S, Weber J. First HIV positive diagnosis coinicident with AIDS: presentation and survival. BMf 1995;311:156-8.

5 Coker RJ, Desmond N, Poznansky M, Smith C, Bell D, Shafi MS. Experience of HIV disease in a London district general hospital. Int $\mathcal{F}$ STD AIDS 1994;5:47-9. 